\title{
Incidence and time trends of type 2 diabetes mellitus in youth aged 5-19 years: a population-based registry in Zhejiang, China, 2007 to 2013
}

Haibin Wu' ${ }^{1}$, Jieming Zhong ${ }^{1}$, Min Yu ${ }^{1}$, Hao Wang ${ }^{1}$, Weiwei Gong ${ }^{1}$, Jin Pan ${ }^{1}$, Fangrong Fei ${ }^{1}$, Meng Wang ${ }^{1}$, Li Yang ${ }^{2}$ and Ruying $\mathrm{Hu}^{1^{*}}$

\begin{abstract}
Background: The incidence of type 2 diabetes mellitus (T2DM) has been increasing globally over the past two decades in children and adolescents. There are currently a dearth of comprehensive population-based estimates of T2DM incidence and time trends in Chinese youth.

Methods: A population-based diabetes registry system in 30 representative districts in Zhejiang has been established for diabetes surveillance. All newly cases diagnosed by physicians in local hospitals and wards were registered using the registry system through web services and direct network report. The data were primarily abstracted from medical records in hospitals and wards. Annual incidence rates and their $95 \%$ confidence intervals (Cls) by age groups and sex were calculated per 100000 person-years. Poisson regression models were applied to assess the effects of diagnosis year, age groups, sex and residence area on T2DM incidence and to examine the average annual percentage change in incidence.

Results: There were 392 newly diagnosed cases of T2DM (210 boys and 182 girls) over the study period. The mean annual age-standardized incidence was 1.96/100 000 person-years (95\% Cls: 1.85-2.08). No statistically significant difference in incidence was found between boys and girls. However, the risk for T2DM was 1.49 times higher in urban area than in rural area. Besides, the mean annual incidence in youth increased with age. The age-standardized incidence was about 5 times higher in 2013 than in 2007. Steep rising incidence was observed, with an average annual increase of $26.6 \%$ in youth aged $10-19$ years.
\end{abstract}

Conclusions: The incidence of T2DM in children and adolescents was low in Zhejiang relative to other countries, whereas it increased markedly over the study period. Preventive strategies for T2DM are necessary in pediatric population.

Keywords: Type 2 diabetes mellitus, Epidemiology, Children and adolescents, China

\section{Background}

Type 2 diabetes mellitus (T2DM) was traditionally considered to be a serious chronic medical condition only for adults. However, increasing incidence of T2DM in children and adolescents has been noted in both developed and developing countries in recent decades [1-4].

\footnotetext{
* Correspondence: ryhu@cdc.zj.cn

'Department of NCDs Control and Prevention, Zhejiang Provincial Center for Disease Control and Prevention, 3399 Binsheng Road, Hangzhou 310051, China

Full list of author information is available at the end of the article
}

Previous reports of T2DM focused primarily on ethnic minority groups, specialized clinical population, and high risk population in specific geographic locations [5-7]. The number of population-based studies in youth was small, in particular in Asian developing countries. Youths with T2DM had longer disease duration and higher risk for complications as compared to adults with T2DM and required lifelong daily treatment, which would place a significant burden on the family, society, and the nation's health care system [8-10]. 
In spite T2DM was still relatively uncommon in youth, the China Health and Nutrition Survey (CHNS) noted that the prevalence of diabetes was already higher in Chinese adolescents than in US adolescents and the comparisons of diabetes across China, South Korea and Taiwan also suggested higher diabetes prevalence in China [11]. There are currently limited comprehensive population-based estimates of T2DM incidence and trends in Chinese youth. As a result, the primary aim of this study was to examine incidence rates and time trends in children and adolescents in registered Zhejiang population for the period 2007-2013 by age, sex, residence area and calendar year, and to compare the results with similar studies conducted in other countries and regions.

\section{Methods}

\section{Data collection}

Zhejiang, one of the most economically prosperous coastal province in China, consists of 90 districts. A prospective population-based diabetes registry system maintained by Zhejiang Provincial Center for Disease Control and Prevention (CDC) has been established for diabetes surveillance in 30 representative districts, covering a population about 16.6 million people.

All newly cases diagnosed by physicians in local hospitals and wards were registered using the registry system through web services and direct network report. In present study, cases were defined as children and adolescents diagnosed as T2DM aged 5-19 years, with a date of diagnosis between 1 January 2007 and 31 December 2013. All cases had elevated blood glucose at least one of the following criteria according to WHO criteria [12]: (1) random plasma glucose $\geq 11.1 \mathrm{mmol} / \mathrm{L} ; \quad$ (2) fasting plasma glucose $\geq 7.0 \mathrm{mmol} / \mathrm{L}$; or (3) 2 -h plasma glucose value after the oral glucose tolerance test $\geq 11.1 \mathrm{mmol} / \mathrm{L}$ and presented classic symptoms were diagnosed as diabetes. Differential diagnosis of T2DM was based on whether they frequently have ketoacidosis at presentation or whether ongoing insulin therapy were required. Furthermore, serology examinations like beta-cell autoantibodies, $\mathrm{C}$-peptide were also taken into consideration. Secondary diabetes (diabetes secondary to another condition e.g., cystic fibrosis, steroid-induced diabetes) were excluded from our study. Before registering, hospital professionals verified cases with diabetes by reviewing their medical records. Finally, patients were followedup by physicians in local community health centers once a year, the diagnosis type could be reevaluated in the process. Besides, a lot of measures have been adopted in diabetes surveillance by Zhejiang CDC, like assessing, supervising and inspecting the process of diagnosis, report and followup in order to ensure the quantity and quality.

The registering data were primarily abstracted from medical records in hospitals. Each individual registered in our system documented the basic properties of hospital, the patients' demographic characteristics, the physician diagnosis and a unique study identification number, etc. In order to ensure our investigation in a homogeneous population of the surveillance districts, we excluded cases that not registered in local resident information system of the 30 surveillance districts based on resident identity number. The data were cleaned up and duplicates within or between the different reporting institutions were identified. Population data of surveillance districts estimated at the end of each year were obtained from Zhejiang Provincial Statistics Bureau by sex, age groups, area of residence and calendar year. The definition of urban and rural areas was based on administrative division in Zhejiang. The main difference was whether the economic activity in regions dominated by agriculture.

Completeness of ascertainment was verified using an alternative source of cases recruited from the underreporting surveys which was an independent survey aimed at evaluating the degree of ascertainment. The registry system provided data for the primary source, and the under-reporting survey provided data for the secondary source. The completeness of ascertainment was calculated according to two-sample capturerecapture method [13]. This study was approved by the Ethics Committee of Zhejiang CDC.

\section{Statistical methods}

The numerator of crude incidence rates were expressed as the number of newly diagnosed cases pooled across all 30 surveillance districts using data from both sources combined. The population registered in local resident information system was regard as denominator. The incidence were calculated separately for three age groups at diagnosis: 5-9, 10-14 and 15-19 years, and also according to sex. The $95 \%$ confidence intervals (CIs) were estimated on the basis of inverting the score test for a binomial proportion [14]. We calculated the standardized incidence rates using the direct standardization method according to the sixth population census in Zhejiang, 2010.

After checking that there was no over-dispersion in the data, Poisson regression models were applied to assess the effects of diagnosis year, age groups, sex and residence area on incidence and to examine the average annual percentage change in incidence. Results were reported as incidence rate ratio (IRR) with 95\% CIs. The exponent of the Poisson regression coefficients and corresponding standard errors were used to derive IRR and their 95\% CIs, which provides a measure of the relative incidence of T2DM in one population group (e.g., boys) compared with another group (e.g., girls). Interactions between diagnosis year and age group, sex, residence area were tested to investigate whether changes over 
time are consistent within these covariates. To examine trends in diabetes incidence across the study period, we treated the calendar year as a continuous variable and tested the statistical significance of the regression coefficient. Statistical analyses were performed using SAS PROC GENMOD (version 9.2, SAS Institute Inc., Cary, NC, USA). $P$-values $<0.05$ were considered statistically significant.

\section{Results}

A total of 392 children and adolescents aged 5-19 years were diagnosed with T2DM (210 boys and 182 girls) during the study period. Using the two-sample capturerecapture method, the completeness of ascertainment for the whole period in all sites was estimated to be 90.5\%. The crude mean annual incidence over the 7 years was 1.73/100 000 person-years (95\% CIs: 1.56-1.91). Standardized mean annual incidence for the same period was 1.96/100 000 person-years (95\% CIs: 1.85-2.08; Table 1).

\section{Sex and residence area}

The crude mean incidence in boys was 1.81/100 000 person-years (95\% CIs: $1.57-2.07)$ and in girls 1.65/100 000 person-years (95\% CIs: 1.42-1.91). Standardized mean annual incidence for the same period was 2.07/ 100000 person-years (95\% CIs: 1.91-2.24) in boys and $1.85 / 100000$ person-years (95\% CIs: $1.69-2.01)$ in girls
(Table 1). In addition, the mean annual incidence were 2.32/100 000 person-years (95\% CIs: 1.98-2.69) and 1.44/100 000 person-years (95\% CIs: $1.25-1.64$ ) in urban and rural area, respectively. There was no statistically significant difference in T2DM incidence between boys and girls when adjusting for other covariates in Poisson regression models, with IRR equal to 1.12 (95\% CIs: 0.92-1.37, $P=0.250$ ). However, the risk for T2DM was 1.49 times (95\% CIs: $1.22-1.82, P<0.001)$ higher in urban area than that in rural area (Table 2).

\section{Age groups}

The mean annual incidence was significantly different across all age groups both in boys and girls $(P<0.001)$, ranged from 0.11/100 000 person-years (95\% CIs: 0.030.28 ) to $4.30 / 100000$ person-years (95\% CIs: $3.69-4.98)$ in boys, and 0.06/100 000 person-years (95\% CIs: 0.01-0.22) to $3.58 / 100000$ person-years (95\% CIs: 3.02-4.21) in girls. The highest incidence was in 15-19 years age group, i.e., 3.94/100 000 person-years (95\% CIs: 3.52-4.40), followed by $10-14$ years, i.e., $0.85 / 100000$ person-years (95\% CIs: $0.65-1.08)$. The least incidence was $0.09 / 100000$ personyears (95\% CIs: 0.03-0.19) in 5-9 years age group (Table 1). Compared with 15-19 years age group, youth aged 10-14 and 5-9 years age groups were at significantly lower risk of T2DM, with adjusting IRR equal to 0.22 (95\% CIs: $0.17-$ 0.29 ) and 0.02 (95\% CIs: 0.01-0.05), respectively (Table 2).

Table 1 Mean annual incidence rate of T2DM in Zhejiang, China (per 100000 person-years)

\begin{tabular}{|c|c|c|c|}
\hline Age (years) & Number of cases & Population at risk (person-years) & Mean annual incidence rate $(95 \% \mathrm{Cl})$ \\
\hline \multicolumn{4}{|l|}{ Boys } \\
\hline $5-9$ & 4 & 3635795 & $0.11(0.03,0.28)$ \\
\hline $10-14$ & 29 & 3873047 & $0.75(0.50,1.08)$ \\
\hline $15-19$ & 177 & 4116374 & $4.30(3.69,4.98)$ \\
\hline $5-19$ & 210 & 11625216 & $1.81(1.57,2.07)$ \\
\hline Standardized incidence ${ }^{a}$ & 637 & 30736608 & $2.07(1.91,2.24)$ \\
\hline \multicolumn{4}{|l|}{ Girls } \\
\hline $5-9$ & 2 & 3307058 & $0.06(0.01,0.22)$ \\
\hline $10-14$ & 35 & 3670059 & $0.95(0.66,1.33)$ \\
\hline $15-19$ & 145 & 4055499 & $3.58(3.02,4.21)$ \\
\hline $5-19$ & 182 & 11032616 & $1.65(1.42,1.91)$ \\
\hline Standardized incidence ${ }^{a}$ & 511 & 27689613 & $1.85(1.69,2.01)$ \\
\hline \multicolumn{4}{|l|}{ All } \\
\hline $5-9$ & 6 & 6942853 & $0.09(0.03,0.19)$ \\
\hline $10-14$ & 64 & 7543106 & $0.85(0.65,1.08)$ \\
\hline $15-19$ & 322 & 8171873 & $3.94(3.52,4.40)$ \\
\hline $5-19$ & 392 & 22657832 & $1.73(1.56,1.91)$ \\
\hline Standardized incidence ${ }^{a}$ & 1146 & 58426221 & $1.96(1.85,2.08)$ \\
\hline
\end{tabular}

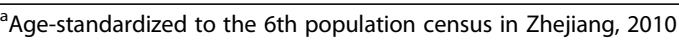


Table 2 Incidence rate ratios (IRR) of T2DM in relation to calendar year and demographic factors

\begin{tabular}{|c|c|c|c|c|c|c|}
\hline \multirow[t]{2}{*}{ Characteristic } & \multicolumn{2}{|l|}{ Boys } & \multicolumn{2}{|l|}{ Girls } & \multicolumn{2}{|l|}{ All } \\
\hline & IRR (95\% Cls) & $P$-value & IRR (95\% Cls) & $P$-value & IRR (95\% Cls) & $P$-value \\
\hline \multicolumn{7}{|l|}{ Year } \\
\hline 2007 & Ref. & & Ref. & & Ref. & \\
\hline 2008 & $1.41(0.62,3.16)$ & 0.411 & $1.12(0.49,2.53)$ & 0.792 & $1.25(0.71,2.23)$ & 0.440 \\
\hline 2009 & $1.59(0.72,3.50)$ & 0.250 & $2.04(0.99,4.21)$ & 0.053 & $1.82(1.07,3.10)$ & 0.027 \\
\hline 2010 & $3.01(1.48,6.15)$ & 0.002 & $3.12(1.58,6.15)$ & 0.001 & $3.06(1.87,5.01)$ & $<0.001$ \\
\hline 2011 & $2.94(1.44,5.99)$ & 0.003 & $3.17(1.61,6.23)$ & 0.001 & $3.05(1.86,4.98)$ & $<0.001$ \\
\hline 2012 & $4.03(2.02,8.02)$ & $<0.001$ & $2.51(1.25,5.05)$ & 0.001 & $3.25(2.00,5.28)$ & $<0.001$ \\
\hline 2013 & $6.23(3.20,12.12)$ & $<0.001$ & $3.66(1.88,7.13)$ & 0.001 & $4.91(3.07,7.84)$ & $<0.001$ \\
\hline \multicolumn{7}{|l|}{ Sex } \\
\hline Girls & & & & & Ref. & \\
\hline Boys & & & & & $1.12(0.92,1.37)$ & 0.250 \\
\hline \multicolumn{7}{|l|}{ Age } \\
\hline $5-9$ ys & $0.03(0.01,0.08)$ & $<0.001$ & $0.02(0.00,0.07)$ & $<0.001$ & $0.02(0.01,0.05)$ & $<0.001$ \\
\hline $10-14$ ys & $0.18(0.12,0.27)$ & $<0.001$ & $0.28(0.19,0.40)$ & $<0.001$ & $0.22(0.17,0.29)$ & $<0.001$ \\
\hline $15-19$ ys & Ref. & & Ref. & & Ref. & \\
\hline \multicolumn{7}{|l|}{ Residence area } \\
\hline Rural & Ref. & & Ref. & & Ref. & \\
\hline Urban & $1.21(0.91,1.59)$ & 0.184 & $1.88(1.41,2.52)$ & $<0.001$ & $1.49(1.22,1.82)$ & $<0.001$ \\
\hline
\end{tabular}

Multivariable Poisson regression model with the calendar year as a dummy variable, bold values indicate statistical significance

\section{Incidence rate trends}

Annual incidence rates and their trends fitted by Poisson regression models separated by sex, age groups and residence area were shown in Table 3 and Table 4. The annual incidence varied widely, alarming increase was observed in each age group during the study period. In Table 3, the age-standardized annual incidence increased from $0.72 / 100000$ person-years (95\% CIs: 0.55-0.93) in 2007 to $3.64 / 100000$ person-years (95\% CIs: 3.24-4.08) in 2013. For 5-9 years age group, given no newly diagnosed cases were observed between 2008 and 2011 in boys and the newly diagnosed cases were only observed in 2013 in girls, we estimated the trends only in 10-14 and 15-19 years age groups. For the 10-19 age group, statistically significant increase in incidence was found, with an average annual increase of $26.60 \%$ (95\% CI: 19.68-33.91; Table 4). Besides, the average annual percentage change decreased with age and it was greater in boys (33.95\%, 95\% CIs: 27.11-41.16) compared with girls (19.23\%, 95\% CIs: 10.92-28.15). Moreover, the incidence in rural area increased $31.58 \%$ (95\% CIs: 24.23-39.93) for each year which was higher than that in urban area (20.87\%, 95\% CIs: 12.50-29.87). However, the 95\% CIs around our point estimation by sex, age group and residence area were quite wide, no statistically significant difference was observed. Finally, no statistically significant difference was found for interactions between diagnosis year and other covariates.
Table 3 Annual incidence rate of T2DM in Zhejiang, China (per 100000 person-years)

\begin{tabular}{llllllll}
\hline Characteristic & Year & & & & & & \\
\cline { 2 - 8 } & 2007 & 2008 & 2009 & 2010 & 2011 & 2012 & 2013 \\
\hline Case number & 21 & 26 & 38 & 65 & 66 & 71 & 105 \\
Boys & 10 & 14 & 16 & 31 & 31 & 43 & 65 \\
Girls & 11 & 12 & 22 & 34 & 35 & 28 & 40 \\
Crude Incidence & 0.62 & 0.77 & 1.14 & 1.95 & 2.03 & 2.30 & 3.62 \\
Standardized Incidence & 0.72 & 0.93 & 1.37 & 2.30 & 2.32 & 2.42 & 3.64 \\
Boys & & & & & & & \\
5-9 years & & & & & & & \\
10-14 years & 0.17 & 0.00 & 0.00 & 0.00 & 0.00 & 0.23 & 0.53 \\
$15-19$ years & 0.18 & 0.18 & 0.18 & 1.07 & 0.71 & 0.36 & 2.73 \\
5-19 years & 1.42 & 2.31 & 2.62 & 4.25 & 4.46 & 6.48 & 8.06 \\
Girls & 0.58 & 0.81 & 0.94 & 1.82 & 1.85 & 2.69 & 4.34 \\
5-9 years & & & & & & & \\
10-14 years & 0.00 & 0.00 & 0.00 & 0.00 & 0.00 & 0.00 & 0.58 \\
15-19 years & 0.73 & 0.74 & 0.93 & 0.56 & 0.19 & 1.98 & 1.69 \\
5-19 years & 1.23 & 1.42 & 2.98 & 5.33 & 5.77 & 3.02 & 5.12 \\
\hline Age-standardized to the & 0.66 & 0.73 & 1.35 & 2.09 & 2.22 & 1.88 & 2.85 \\
\hline
\end{tabular}

${ }^{\mathrm{a}}$ Age-standardized to the 6 th population census in Zhejiang, 2010 
Table 4 Average annual percentage change of T2DM incidence by demographic factors

\begin{tabular}{|c|c|c|c|c|}
\hline \multirow[t]{2}{*}{ Characteristic } & \multirow{2}{*}{$\begin{array}{l}\text { Average annual } \\
\text { percentage change (\%) }\end{array}$} & \multicolumn{2}{|l|}{$95 \% \mathrm{Cls}$} & \multirow[t]{2}{*}{$P$-value } \\
\hline & & Lower (\%) & Upper (\%) & \\
\hline \multicolumn{5}{|l|}{ Boys } \\
\hline $10-14$ ys & 57.99 & 29.50 & 92.74 & $<0.001$ \\
\hline $15-19$ ys & 30.75 & 25.09 & 36.67 & $<0.001$ \\
\hline $10-19$ ys & 33.95 & 27.11 & 41.16 & $<0.001$ \\
\hline \multicolumn{5}{|l|}{ Girls } \\
\hline $10-14$ ys & 18.84 & 1.04 & 39.77 & 0.037 \\
\hline $15-19$ ys & 19.44 & 10.56 & 29.02 & $<0.001$ \\
\hline $10-19$ ys & 19.23 & 10.92 & 28.15 & $<0.001$ \\
\hline \multicolumn{5}{|c|}{ Area of residence } \\
\hline Rural & 31.85 & 24.23 & 39.93 & $<0.001$ \\
\hline Urban & 20.87 & 12.50 & 29.87 & $<0.001$ \\
\hline \multicolumn{5}{|l|}{ All } \\
\hline $10-14$ ys & 33.40 & 13.09 & 57.35 & 0.001 \\
\hline $15-19$ ys & 25.38 & 18.75 & 32.38 & $<0.001$ \\
\hline $10-19$ ys & 26.60 & 19.68 & 33.91 & $<0.001$ \\
\hline
\end{tabular}

Multivariable Poisson regression models with the calendar year as a continuous variable and adjusting for the other covariates. Bold values indicate statistical significance

\section{Discussion}

The observed findings indicated an alarming increase of T2DM in Zhejiang, although the overall incidence was low relative to some western countries. Our study implied that a huge burden the health care system will need to confront in pediatric population. The mean annual agestandardized incidence was found to be 1.96/100 000 person-years in youth aged 5-19 years. The incidence calculated from a multiethnic, population-based study (The SEARCH for Diabetes in Youth Study) in US was 7.0/100 000 person-years in youth aged 5-19 years between 2002 and 2003 [15]. Moreover, the overall age-adjusted annual incidence of T2DM was 9.6/100 000 person-years in youth $\leq 19$ years in US Virgin Islands, 2001-2010 [16]. Nevertheless, the incidence in Canada has been reported to be 1.54/100 000 person-years in children and adolescents $<18$ years [17], similar to the incidence of children $<$ 15 years in Auckland, New Zealand (1.3/100 000 personyears) [18]. Furthermore, the childhood incidence in England was substantially higher for blacks (3.9/100 000 person-years) and South Asians (1.25/100 000 personyears) compared with whites (0.35/100 000 person-years) between 2004 and 2005 [19]. In Asia, a study based on urine glucose screening in the Tokyo metropolitan area reported the overall annual incidence of 2.63/100 000 person-years for school children [20]. The variation around the world may contribute to the racial and ethnic difference, research design, study period and the T2DM diagnosis, etc.
In our study, the age-standardized incidence was about five times higher in 2013 than that in 2007, with an average annual increase of $26.60 \%$ in $10-19$ years of age. This was considerably greater than data from other worldwide population. In New Zealand, the incidence of T2DM increased by five-fold during 1995 to 2007 in children and adolescents [18]. Additionally, between 1995 and 2007, the annual incidence in children < 15 years also increased five-fold in SEARCH in US [15]. In US Virgin Islands, the incidence increased nearly 2.5 times from 2001 to 2005 to 2006-2010 periods for nonHispanic Black youth [16]. A study in UK reviewing the first hospital admissions with a diagnosis of T2DM in patients aged 0 to 18 years indicated a significant rise between 1996 and 1997 and 2003-2004, especially since 2001 [21]. Furthermore, the results based on 14 multicenter hospital data from 1995 to 2010 in China showed that the prevalence of new-onset T2DM doubled for youth younger than 18 years in the latest 5 year [7].

T2DM is a complex metabolic disorder of heterogenous etiology with social, behavioral, and environmental risk factors unmasking the effects of genetic susceptibility [22]. Despite alarming increase in incidence may contribute to the very low base-year incidence based on limited number of cases, many risk factors such as foetal and early-life influences, ethnic difference, family history of diabetes, childhood obesity, decreased physical activity and environment factors are responsible [23]. Recent evidence suggests an emerging epidemic of childhood T2DM in parallel with the childhood obesity epidemic $[21,24]$. Zhejiang is one of the most economically prosperous coastal province in China, the industrialization and urbanization developed quickly in recent years. Besides, changes in diet and decreased physical activity resulted in more pediatric obesity. The Chinese National Surveys on Students' Constitution and Health $(\mathrm{CNSSCH})$ reported the age-adjusted prevalence of obesity and of overweight and obesity combined in 2010 was $8.1 \%$ and $19.2 \%$ among children and adolescents aged 7-18 years [25], steepest increase in more economically prosperous coastal cities was found: from $3.8 \%$ in 1985 to $32.6 \%$ in 2010 for boys and $3.0 \%$ to $19.1 \%$ for girls [26]. Based on HbA1c, the CHNS observed the pre-diabetes rate of $14.9 \%$ in adolescents aged 7-17 years [11]. On the other hand, increasing childhood obesity may be given the substantial attention to T2DM in recent years, it was possible for unclear cases to be diagnosed as T2DM rather than T1DM. Beyond that, with the improvement of health care facilities, medical insurance systems, clinical detection and awareness of heath in Zhejiang, children and adolescents with diabetes were diagnosed more immediately and accurately than before.

During the study period, a faster annual increasing was identified in boys and rural area, and the average annual percentage change decreased with age in the 
point estimation of Poisson regression models. Similarly, a study in west Yorkshire, UK reported a faster increase for children aged 0-14 (37.4\%) compared with those aged 15-19 (18.1\%) between 1991 and 2006. [27]. The result implied that the onset age of T2DM became younger. However, the $95 \%$ CIs of our estimation by sex and age group were quite wide, which indicated the difference was not statistically significant due to the relatively short period of observation and inadequate cases.

The present study showed the mean annual incidence in youth increased with age. The results consisted with SEARCH project in US, in which the overall annual incidence rate per 100000 person-years were $0.8,8.1$ and 11.8 for $5-9,10-14$ and $15-19$ years age group, respectively [15]. Moreover, the investigation in Japan found the annual incidence was significantly higher for junior high school students compared with primary school students ( 0.78 vs 6.43/100 000 person-years) [20]. The phenomenon may be caused by puberty which is considered to be an important risk factor leading to glucose intolerance. It was reported that insulin sensitivity decreases about 30\% during puberty, resulting in hyperinsulinemia [28-30].

Despite the age-standardized incidence was higher in boys than in girls, no statistically significant difference was observed. Similar to our results, there were no statistically significant difference between sex in Japan and US Virgin Islands' reports [16, 20]. However, the surveillance in Taiwan province found girls had greater risk than boys $(\mathrm{OR}=1.62)$ [31]. In contrast, the study based on 14 multicenter hospital data in China reported the prevalence of new-onset T2DM in boys was significantly higher than in girls [7]. Compared with population living in rural area, the IRR of T2DM increased to 1.19 for those living in urban area. The results could be partly explained by the results that obesity was more likely to be present among children and adolescents who were boys and lived in urban from $\mathrm{CNSSCH}$ [25].

The diabetes registry system was the primary source of data on the incidence and trends of diabetes in the territory. We utilized data from medical records to update the registry. This presented several limitations for consideration. First, in the earlier time points, people did not go to hospital until they had obviously clinical manifestations, meanwhile, there were no routine physical examinations for them. Therefore, the diagnosis time may be delayed and it was difficult to estimate the fraction of undiagnosed diabetes without related screening. As frequent mild or asymptomatic manifestation of T2DM in childhood [32, 33], our passive surveillance registry may underestimate the incidence, especially in the earlier time points. Therefore, a screening seems meaningful especially in overweight and obesity youth at onset of puberty. Second, this analysis was limited by short study period and inadequate cases, especially in various subgroups, including age and calendar year categories. In multivariable Poisson regression models, the regression coefficients for average annual increase had large standard error leading to quite wide 95\% CIs. Therefore, 95\% CIs for point estimation should be referenced.

\section{Conclusions}

This study examined the incidence rate and time trends of T2DM over a 7 year period in a population-based registry in Zhejiang, China. An alarming increasing in incidence was observed, although the overall incidence was low relative to other countries. The mean annual incidence in youth increased with age. Children and adolescents living in urban area had a greater risk of T2DM compared with those living in rural area. Preventive strategies for T2DM are necessary in pediatric population.

\section{Abbreviations}

CDC: Center for disease control and prevention; CHNS: China health and nutrition survey; CNSSCH: Chinese national surveys on students' constitution and health; T2DM: Type 2 diabetes mellitus

\section{Acknowledgements}

The authors thank the colleagues at district Provincial Center for Disease Control and Prevention in all 30 surveillance districts for their important contributions.

\section{Funding}

This study was supported by the national key research and development program of China "major chronic non-communicable disease prevention and control research" (2016YFC1305301); national key research and development program of China "precision medical research" (2016YFC0901200, 2016YFC0901205)

\section{Availability of data and materials}

The datasets used and/or analysed during the current study available from the corresponding author on reasonable request.

\section{Authors' contributions}

HW contributed to the conception and design of the study, data analysis and preparing of the manuscript. JZ gave much advice and directions in both study design and manuscript revision. MY gave much advice and directions in both study design and manuscript revision. HW contributed to data collection and study conduct. WG contributed to data collection and study conduct. JP contributed to data collection and study conduct. FF contributed to data collection and study conduct. MW contributed to data collection and study conduct. LY gave much advice and directions in both study design and manuscript revision. $\mathrm{RH}$ contributed to the conception and design of the study and data analysis. All authors read and approved the final manuscript.

\section{Competing interests}

The authors declare that they have no competing interests.

Consent for publication

Not applicable.

Ethics approval and consent to participate

This study was approved by the ethics committee of Zhejiang Provincial Center for Disease Control and Prevention.

\section{Publisher's Note}

Springer Nature remains neutral with regard to jurisdictional claims in published maps and institutional affiliations. 


\section{Author details}

'Department of NCDs Control and Prevention, Zhejiang Provincial Center for Disease Control and Prevention, 3399 Binsheng Road, Hangzhou 310051, China. ${ }^{2}$ Zhejiang Provincial Center for cardio-cerebrovascular diseases control and prevention, Zhejiang Hospital, 12 Lingyin Road, Hangzhou 310013, China.

Received: 4 November 2015 Accepted: 8 March 2017

Published online: 22 March 2017

\section{References}

1. Rosenbloom AL, Young RS, Joe JR, Winter WE. Emerging epidemic of type 2 diabetes in youth. Diabetes Care. 1999;22:345-54.

2. Pinhas-Hamiel O, Zeitler P. The global spread of type 2 diabetes mellitus in children and adolescents. J Pediatr. 2005;146:693-700.

3. Nadeau K, Dabelea D. Epidemiology of type 2 diabetes in children and adolescents. Endocr Res. 2008;33:35-58.

4. Dileepan K, Feldt MM. Type 2 diabetes mellitus in children and adolescents. Pediatr Rev. 2013;34:541-8.

5. Liu LL, Yi JP, Beyer J, et al. Type 1 and Type 2 diabetes in Asian and Pacific Islander US youth: the SEARCH for diabetes in youth study. Diabetes Care. 2009;32(Suppl2):S133-40

6. Lipton R, Keenan H, Onyemere KU, Freels S. Incidence and onset features of diabetes in African-American and Latino children in Chicago, 1985-1994. Diabetes Metab Res Rev. 2002;18:135-42.

7. Fu JF, Liang L, Gong CX, et al. Status and trends of diabetes in Chinese children: analysis of data from 14 medical centers. World J Pediatr. 2013;9:127-34

8. Rosenbloom AL, Silverstein JH, Amemiya S, Zeitler P, Klingensmith GJ. ISPAD Clinical Practice Consensus Guidelines 2006-2007. Type 2 diabetes mellitus in the child and adolescent. Pediatr Diabetes. 2008:9:512-26.

9. Hillier TA, Pedula KL. Complications in young adults with early-onset type 2 diabetes: losing the relative protection of youth. Diabetes Care. 2003;26: 2999-3005.

10. Eppens MC, Craig ME, Cusumano J, et al. Prevalence of diabetes complications in adolescents with type 2 compared with type 1 diabetes. Diabetes Care. 2006:29:1300-6.

11. Yan S, Li S, Zhang B, et al. The expanding burden of cardiometabolic risk in China: the China Health and Nutrition Survey. Obes Rev. 2012;13:810-21.

12. World Health Organization. Definition, diagnosis and classification of diabetes mellitus and its complications: report of a WHO consultation. Part 1. Diagnosis and classification of diabetes mellitus. Geneva: World Health Organization; 1999.

13. International Working Group for Disease Monitoring and Forecasting. Capture-recapture and multiple-record systems estimation II: applications in human disease. Am J Epidemiol. 1995;142:1059-68.

14. Agresti A, Coull BA. Approximate is better than "exact" for interval estimation of binomial proportions. Am Stat. 1998:52:119-26.

15. Writing Group for the SEARCH for Diabetes in Youth Study Group, Dabelea D, Bell RA, D'Agostino Jr RB, et al. Incidence of diabetes in youth in the United States. JAMA. 2007;297:2716-24.

16. Washington RE, Orchard TJ, Arena VC, Laporte RE, Tull ES. Incidence of type 1 and type 2 diabetes in youth in the US Virgin Islands, 2001-2010. Pediatr Diabetes. 2013;14:280-7.

17. Amed S, Dean HJ, Panagiotopoulos C, et al. Type 2 diabetes, medication-induced diabetes, and monogenic diabetes in Canadian children: a prospective national surveillance study. Diabetes Care. 2010;33:786-91.

18. Jefferies C, Carter P, Reed PW, et al. The incidence, clinical features, and treatment of type 2 diabetes in children $<15 \mathrm{yr}$ in a population-based cohort from Auckland, New Zealand, 1995-2007. Pediatr Diabetes. 2012;13:294-300.

19. Haines L, Wan KC, Lynn R, Barrett TG, Shield JP. Rising incidence of type 2 diabetes in children in the U.K. Diabetes Care. 2007;30:1097-101.

20. Urakami T, Kubota S, Nitadori Y, Harada K, Owada M, Kitagawa T. Annual Incidence and Clinical Characteristics of Type 2 Diabetes in Children as Detected by Urine Glucose Screening in the Tokyo Metropolitan Area. Diabetes Care. 2005;28:1876-81.

21. Aylin P, Williams S, Bottle A. Obesity and type 2 diabetes in children, 1996-7 to 2003-4. BMJ. 2005;331:1167.

22. Kiess W, Böttner A, Raile $K$, et al. Type 2 diabetes mellitus in children and adolescents: a review from a European perspective. Horm Res. 2003;59:77-84.
23. Daneman D. State of the World's Children with Diabetes. Pediatr Diabetes 2009:10:120-6.

24. Praveen PA, Kumar SR, Tandon N. Type 2 diabetes in youth in South Asia. Curr Diab Rep. 2015;15:571.

25. Sun $H, M a Y$, Han D, Pan CW, Xu Y. Prevalence and trends in obesity among China's children and adolescents, 1985-2010. PLoS ONE. 2014;9, e105469.

26. Ji CY, Chen TJ, Working Group on Obesity in China (WGOC). Empirical Changes in the Prevalence of Overweight and Obesity among Chinese Students from 1985 to 2010 and Corresponding Preventive Strategies. Biomed Environ Sci. 2013;26:1-12.

27. Harron KL, Feltbower RG, McKinney PA, Bodansky HJ, Campbell FM, Parslow RC. Rising Rates of All Types of Diabetes in South Asian and Non-South Asian Children and Young People Aged 0-29 Years in West Yorkshire, U.K 1991-2006. Diabetes Care. 2011;34:652-4.

28. Amiel SA, Sherwin RS, Simonson DC, Lauritano AA, Tamborlane WV Impaired insulin action in puberty: a contributing factor to poor glycemic control in adolescents with diabetes. N Engl J Med. 1986;315:215-9.

29. Bloch CA, Clemons P, Sperling MA. Puberty decreases insulin sensitivity. J Pediatr. 1987;110:481-7.

30. Arslanian SA. Type 2 diabetes mellitus in children: pathophysiology and risk factors. J Pediatr Endocrinol Metab. 2000;13:1385-94

31. Wei JN, Sung FC, Lin CC, Lin RS, Chiang CC, Chuang LM. National Surveillance for Type 2 Diabetes Mellitus in Taiwanese Children. JAMA. 2003:290:1345-50.

32. Sinha $R$, Fisch $G$, Teague $B$, et al. Prevalence of impaired glucose tolerance among children and adolescents with marked obesity. N Engl J Med. 2002;346:802-10.

33. Wabitsch $\mathrm{M}$, Hauner $\mathrm{H}$, Hertrampf $\mathrm{M}$, et al. Type II diabetes mellitus and impaired glucose regulation in Caucasian children and adolescents with obesity living in Germany. Int J Obes Relat Metab Disord. 2004:28:307-13.

\section{Submit your next manuscript to BioMed Central and we will help you at every step:}

- We accept pre-submission inquiries

- Our selector tool helps you to find the most relevant journal

- We provide round the clock customer support

- Convenient online submission

- Thorough peer review

- Inclusion in PubMed and all major indexing services

- Maximum visibility for your research

Submit your manuscript at www.biomedcentral.com/submit 